\title{
Avaliando Acessibilidade em Sistemas de Comunicação com Usuários Cegos
}

\section{Simone Bacellar Leal Ferreira ${ }^{1}$, Denis Silva da Silveira ${ }^{2}$, Ricardo Rodrigues Nunes $^{3}$, Claudia Simões Pinto da Cunha Lima ${ }^{1}$}

${ }^{1}$ Depto. de Informática Aplicada - Universidade Federal do Estado do Rio de Janeiro (UNIRIO)

Rio de Janeiro - RJ - Brasil

${ }^{2}$ Departamento de Ciência da Informação - Universidade Federal de Pernambuco (UFPE)

$$
\text { Recife - PE - Brasil }
$$

${ }^{3}$ Departamento de Engenharias - Universidade de Trás-os-Montes e Alto Douro (UTAD)

$$
\begin{aligned}
& \text { Vila Real - Trás-os-Montes e Alto Douro - Portugal } \\
& \text { simone@uniriotec.br, denis.silveira@ufpe.br, rrnunes@utad.pt, } \\
& \text { claudiaspcldgmail.com }
\end{aligned}
$$

\begin{abstract}
Presently the organizations are using information systems to communication your customers. But these system needs to be accessible to different users, because somebody can has physical, motor, auditory or visual limitations. The present research aims to evaluate the way by which visually handicapped people interact in chat systems. Two chats were selected for evaluation, SACI chat and TERRA chat. The results lead to the identification of problems blocking and making it difficult to access and to understand the web content and collaboration. They lead to the possibility of suggesting a number of points that contribute to making group-management web systems easier to access and to be used by people with total visual deficiency.
\end{abstract}

Resumo. É possível perceber que muitas organizações estão tirando proveito dos Sistemas de Informação para facilitar a comunicação e o relacionamento com seus clientes. Mas é importante lembrar que esses sistemas deverão atender diferentes pessoas, sendo que algumas delas podem ter limitações fisica, motora, auditiva ou visual. A presente pesquisa teve por objetivo avaliar como as pessoas cegas interagem com os sistemas de conversação da rede SACI e do site TERRA. Foram identificados problemas que podem impedir ou dificultar o acesso e o entendimento do conteúdo e gerou-se recomendações que podem contribuir para que os sistemas sejam mais acessíveis e de fácil uso para esse grupo de pessoas.

\section{Introdução}

Quando uma pessoa acessa um Sistema de Informação, ela espera atingir seus objetivos. Se a experiência for agradável e a Interface for acessível e de fácil compreensão, há grandes chances do sistema ser usado e compartilhado por várias 
pessoas. A Interface é o meio pelo qual se consegue estabelecer um diálogo entre o ser humano e o sistema [Rocha e Baranauskas 2003].

Atualmente, é possível perceber que muitas organizações estão tirando proveito - cada vez mais - dos Sistemas de Informação para facilitar a comunicação "estreitando", dessa forma, o relacionamento com seus clientes. O chat ou simplesmente "bate-papo" é um dos exemplos de sistemas deste tipo que - quando utilizado em um Serviço de Atendimento ao Cliente (SAC) - atua como um facilitador na comunicação de pessoas em tempo real [Pimentel 2006]. Mas, é importante lembrar que esses sistemas deverão atender às diferentes pessoas e algumas delas podem ter limitações física, motora, auditiva ou visual.

As Interfaces devem poder ser acessadas por qualquer pessoa, independentemente de suas capacidades físico-motoras, perceptivas, culturais e sociais [Nicholl 2001]. Os projetistas de sistemas devem concentrar-se nos usuários [Norman 1999] [Norman e Draper 1986], procurar saber quem são; como realizam suas tarefas; qual sua percepção dos sistemas e, naturalmente, a que tipos de imposições e limitações estão sujeitos [Laurel 1990]. As limitações dos usuários não só influenciam na maneira de realizar a navegação nos sistemas, mas também na percepção do conteúdo disponível e consequentemente na captação da informação.

Acessibilidade é a possibilidade de qualquer pessoa usufruir todos os benefícios da sociedade, inclusive o de usar a Internet. Um sistema é considerado acessível quando não possui impedimentos para o acesso dos usuários, distinguindo da usabilidade que está relacionado à facilidade de uso do sistema [Leal Ferreira et al. 2007].

Antes das novas tecnologias, tais como a internet, os cegos só podiam ler livros, jornais e revistas com a ajuda de um ledor (pessoa que lê para cegos). Com o avanço dos recursos digitais, como os programas leitores de tela, o cego conquistou a liberdade de fazer suas leituras sozinho [Leal Ferreira e Nunes 2008].

A acessibilidade digital não é tão simples. Algumas pessoas possuem limitações sensoriais e motoras que precisam ser compensadas de alguma forma para que possam ter acesso aos recursos computacionais, e para isso as organizações necessitam adaptar seus recursos computacionais a fim de tornar o uso do computador acessível a todos tipos de usuários, como por exemplo, usuários com deficiências visuais [Harrison 2005]. Como essa adaptação requer conhecimento técnico e pessoal especializado, muitas vezes as organizações não dedicam os esforços necessários ao processo de acessibilização [Leal Ferreira e Nunes 2008].

A presente pesquisa, de caráter exploratório, teve por objetivo avaliar como os cegos interagem com sistemas, em especial os sistemas computacionais de comunicação. Selecionou-se dois sistemas de conversação para serem avaliados, o site da rede SACI (intervox.nce.ufrj.br) e do site TERRA (http://www.terra.com.br). Buscou-se identificar possíveis problemas que podem impedir ou dificultar o acesso e o entendimento do conteúdo e gerou-se recomendações que podem contribuir para o desenvolvimento de sistemas mais acessíveis e de fácil uso para esse grupo de pessoas.

A pesquisa foi realizada com cinco usuários cegos. Este total de usuários foi definido considerando-se as recomendações propostas por Jakob Nielsen que afirma que 
acima deste número, são poucos os problemas relevantes que os demais usuários iriam detectar; os problemas começam a ser repetitivos [Nielsen 2000].

\section{Acessibilidade}

Acessibilidade é a possibilidade de qualquer pessoa, independentemente de suas capacidades físico-motoras, perceptivas, culturais e sociais, usufruir os benefícios de uma vida em sociedade e de participar de todas as atividades, até as que incluem o uso de produtos, serviços e informação, com o mínimo de restrições [Nicholl 2001] [ABNT 2004]. Essa definição, proposta inclusive pela Associação Brasileira de Normas Técnicas (ABNT), apesar de muito rigorosa, é fundamental, pois a acessibilidade só existe de fato quando "todos" conseguem acesso a esses benefícios [Queiroz 2010].

A acessibilidade digital é mais específica e refere-se apenas ao acesso aos recursos computacionais. $\mathrm{O}$ termo acessibilidade na Internet é usado, de forma ampla, para definir o acesso universal a todos os componentes da rede mundial de computadores, como chats, e-mail, entre outros. Já o termo acessibilidade na $W e b$, ou eacessibilidade, refere-se especificamente ao componente $W e b$, que é um conjunto de páginas escritas na linguagem HTML e interligadas por links de hipertexto. A acessibilidade na Web representa para o usuário o direito de acessar a rede de informações e de eliminar barreiras arquitetônicas, de disponibilidade de comunicação, de acesso físico, de equipamentos e programas adequados, de conteúdo e apresentação da informação em formatos alternativos [Nevile 2005] [Sales e Cybis 2003].

No final da década de 1990, começaram-se a realizar alguns estudos, tanto no âmbito internacional como no nacional, sobre a acessibilidade digital e na Internet. Com o objetivo de tornar a Web acessível a todos, o W3C criou, em 1999, o WAI (Web Accessibility Initiative), grupos de trabalho voltados para a elaboração de diretrizes ligadas à garantia da acessibilidade na $W e b$ [Nevile 2005] [ENAP 2007]. O WAI elaborou o "Estatuto de Recomendação do W3C", (Web Accessibility Content Guidelines - WCAG 1.0), a primeira versão das Diretrizes para a Acessibilidade do Conteúdo da Web, lançada em maio de 1999; em dezembro de 2008 foi lançada sua segunda versão [W3C 2010].

No Brasil, a acessibilidade começou fazer parte das políticas públicas a partir do ano 2000, com a promulgação das Leis Federais $\mathrm{n}^{\mathbf{0}} 10.048$ e 10.098, que abordam questões de acessibilidade. Em dezembro de 2004, as duas legislações foram regulamentadas pelo decreto $\mathrm{n}^{0} 5.296$, que estabeleceu um prazo de doze meses para que todos os portais e sites eletrônicos da administração pública passassem por um processo de acessibilização; esse prazo foi prorrogado por mais doze meses [Queiroz 2010]. Com a finalidade de se dedicar à normalização da acessibilidade, criou-se também o Comitê CB-40, da ABNT surgindo então o Modelo de Acessibilidade Brasileiro (e-MAG) [ENAP 2007].

\section{Interação Deficientes Visuais-Máquina}

A facilidade do usuário de interagir com uma Interface depende tanto dos aspectos de usabilidade como também de sua capacidade de detectar e interpretar as informações do sistema e responder apropriadamente a elas. Como, no ambiente computacional, grande 
parte da informação se apresenta na forma visual, a habilidade nessa área relaciona-se intimamente a uma cadeia complexa de processos visuais [Leal Ferreira e Nunes 2008].

Como a visão é o principal meio de interagir com os sistemas, por melhor que seja o projeto da Interface, ela não estará de acordo com o modelo conceitual dos usuários cegos e sempre se constituirá uma barreira para eles. Como as Interfaces gráficas impedem ou, na melhor das hipóteses, dificultam o acesso desses usuários, estes, para interagir com os sistemas, necessitam de uma tecnologia de apoio capaz de captar as Interfaces gráficas e torná-las acessíveis. O usuário comum, ao acessar uma página na $W e b$, usa um navegador (browser), enquanto o acesso de um usuário cego exige uma tecnologia assistiva ou de apoio de outro usuário com visão.

Tecnologia assistiva consiste de qualquer ferramenta ou recurso destinado a proporcionar habilidades funcionais aos deficientes, ou ampliar as existentes, e assim dar-lhes maior autonomia [ENAP 2007]. Os usuários cegos, ao interagirem com sistemas, utilizam softwares denominados "programas leitores de tela" (screen readers) associados a outros programas chamados de "sintetizadores de voz". Os programas leitores de tela captam e interpretam o código relacionado à informação exibida na tela do computador e, por meio dos sintetizadores de voz, disponibilizam a informação em forma de som.

Logo, as Interfaces devem ser projetadas de forma que, quando acessadas por uma tecnologia assistiva, como um leitor de tela, continuem fornecendo uma interação "amigável". Elas devem fornecer sequências simples e consistentes de interação, mostrando claramente as alternativas a cada passo, sem confundir nem deixar o usuário inseguro; o usuário deve poder se fixar somente no problema que deseja resolver [Leal Ferreira e Nunes 2008].

\subsection{Programas Avaliadores de Acessibilidade}

Como é importante que se projete Interfaces em conformidade com as diretrizes de acessibilidade e visando à usabilidade, é necessário que as mesmas tenham sua acessibilidade verificada. Com base nas recomendações do W3C/WAI, foram desenvolvidos programas para avaliar o nível de acessibilidade dos sites. Esses programas detectam o código HTML e analisam seu conteúdo, verificando se está ou não de acordo com o conjunto das regras estabelecidas; no final, eles geram relatórios com uma lista dos problemas encontrados, que devem ser corrigidos para que o site possa ser considerado acessível [Leal Ferreira e Nunes 2008].

Entre esses softwares, destacam-se: WebXact, o Hera e o Cynthia Says. No Brasil, criou-se o programa daSilva, que avalia os sites de acordo com as regras de acessibilidade estabelecidas pelo WCAG e pelo e-MAG [Leal Ferreira e Nunes 2008]. Existem também ferramentas que, além de possuírem um validador automático, conseguem simular a navegação de usuários cegos, como exemplo, o sistema aDesigner [aDesigner 2008].

\subsection{Importância de Conhecer os Usuários com Deficiências}

Usuários com deficiência, ao acessarem um sistema, utilizam um ambiente bem diferente do das pessoas sem deficiência; esses usuários criam suas percepções do sistema e seus modelos baseados na maneira peculiar com que interagem com o sistema 
a fim de suprir suas necessidades. Como os demais usuários, eles relacionam os elementos computacionais com "objetos" de seu dia-a-dia, mas, no caso, muitas vezes se trata de "objetos" criados com o propósito específico de compensar suas carências. Além disso, certas deficiências, como a cegueira, levam ao desenvolvimento de habilidades especiais, como uma excelente audição ou a facilidade de manusear uma combinação complexa de teclas. Essas habilidades incomuns, por sua vez, pelo fato de acrescentar mais uma dificuldade na interação com sites, acabam também influenciando seus modelos conceituais [Takagi 2004].

Como a percepção do sistema sofre influência das várias experiências da pessoa, cada usuário acaba criando o próprio modelo conceitual; como é pouco provável que pessoas sem deficiências tenham, ao navegar pela Internet, uma experiência semelhante à de pessoas com deficiências, os modelos conceituais de pessoas com deficiências tendem a ser distintos dos modelos das demais pessoas [Takagi 2004]. Por exemplo, a metáfora da janela (windows), usada para indicar a possibilidade de visualizar uma área de trabalho, nada representa para um cego [Leal Ferreira e Nunes 2008].

A verificação da acessibilidade de um site feita somente por programas avaliadores de acessibilidade não necessariamente garantirá um acesso a todos nem uma facilidade de uso. Porém, a atenção excessiva dada à acessibilidade acabou criando regulamentações que contribuíram para melhorar a acessibilidade, mas sem melhorar a facilidade de uso, uma vez que a conformidade com as diretrizes se tornou o principal objetivo dos programas avaliadores de acessibilidade. Além disso, muitos programas avaliadores dependem unicamente de técnicas de verificação sintática das páginas para medir a acessibilidade. Com isso, os erros detectáveis se limitam à camada de descrição de etiquetas (tags). Esses programas geralmente verificam somente se as etiquetas HTML estão sendo usadas de acordo com as determinações das diretrizes, sem prestar atenção na usabilidade. E para agravar essa situação, raramente os usuários se sentam e escutam a saída falada de forma passiva; eles se movimentam pelas páginas usando uma série de combinações de teclas. É por meio desse processo que eles criam seus modelos mentais e tentam navegar de forma lógica pelas páginas. Os programas avaliadores de acessibilidade desconsideram esse fator.

Em sistemas orientados à usabilidade, a percepção que o usuário tem deve ser o mais próxima possível do sistema em si. Cabe, portanto ao projetista procurar conhecer bem os usuários finais para compreender sua percepção do sistema, isto é, seu modelo conceitual. Desse modo, quando se trata de usuários com deficiência, torna-se fundamental identificar quais são as suas necessidades e habilidades especiais [Takagi 2004]. Ou seja, é preciso tentar descobrir que barreiras que esses usuários precisam superar para acessar a informação, a fim de possibilitar o desenvolvimento de Interfaces fáceis de usar para eles [Harrison 2005]. Este artigo mostra alguns resultados, obtidos ao se conhecer melhor usuários cegos, e que contribuem para facilitar a interação destas pessoas com sistemas.

\section{Método da Pesquisa}

O estudo, de caráter exploratório, teve seis etapas [Pinto 2009]: a) escolha dos usuários; b) definição das técnicas e ferramentas; c) definição dos sistemas para estudo; d) avaliação automática dos sistemas com um simulador automático; e) avaliação dos 
sistemas com usuários cegos; f) análise dos resultados através de uma comparação entre as avaliações.

\subsection{Etapas do Método}

(a) Após o levantamento bibliográfico e documental inicial, houve a necessidade de restringir as análises a uma única deficiência, assim, optou-se por avaliar a interação de usuários com cegos pelo fato de poder gerar contribuições que possam favorecer o fácil acesso à Internet. As sessões de testes foram realizadas com cinco participantes cegos, sendo todos usuários da Internet com acesso diário variando de 1 a 12 horas. A faixa etária dos pesquisados está entre 24 e 60 anos, sendo três estudantes universitários, um professor e consultor de acessibilidade e um que atua na área de psicologia clínica. Todos informaram, em entrevista, que usam a $W e b$ para acessar e-mail e ler notícias. Apenas um usuário utiliza sistemas de jogos on-line, um faz compras pela Internet e três deles participam de grupos de discussão. A escolha dessas pessoas se deu pelo relato da experiência deles com a Internet e pela facilidade de acesso à rotina desses estudantes e profissionais.

(b) Definição das Técnicas e Ferramentas: Com base na pesquisa bibliográfica, foram defininidas três técnicas usadas. Para facilitar o entendimento, as técnicas foram numeradas. Assim, as técnicas 1 e 2 foram aplicadas na avaliação com os usuários cegos e a técnica 3 foi usada na avaliação com a ferramenta automatizada.

Técnica 1 (ensaio de interação): permite a participação efetiva do usuário em sessões de testes e observação [Cybis et al. 2007]. Essa técnica foi usada com o objetivo de analisar a maneira como os usuários interagem com os sistemas e, assim, identificar obstáculos que dificultam ou impedem a compreensão do conteúdo. Durante as sessões, com tempo de duração variável, os usuários executaram as tarefas, apresentadas na Tabela 1. Foi observado apenas um único usuário por vez. As sessões de teste foram gravadas em arquivos de vídeo, através de sistema que captura as telas e o áudio, para posterior análise. Após finalização das tarefas foi aplicado um questionário para todos os usuários com a finalidade de contextualizar os testes.

Tabela 1. Tarefas Executadas nas Seções de Testes.

\begin{tabular}{|c|c|c|c|}
\hline Tarefa & Sistemas & Descrição da Tarefa & Objetivo \\
\hline 1 & SACI & $\begin{array}{c}\text { Você deve usar a opção via navegador para enviar uma mensagem } \\
\text { reservada para qualquer participante. Apenas digite "oi". }\end{array}$ & Envio de mensagem. \\
\hline 2 & TERRA & $\begin{array}{c}\text { Escolha uma sala e envie a pergunta: "Qual o site de busca que } \\
\text { vocês usam para pesquisar?". Aguarde a resposta. }\end{array}$ & $\begin{array}{c}\text { Envio de mensagens, que dá apoio ao } \\
\text { diálogo, leitura. }\end{array}$ \\
\hline
\end{tabular}

Técnica 2 (pensando em voz alta): foi usada concomitantemente com a segunda técnica, ensaio de interação e também tem como objetivo analisar a maneira como os usuários interagem com os sistemas. Esse método, recomendado em quase todos os testes de usabilidade [Nielsen e Loranger 2007], consiste em solicitar ao usuário-teste pensar em voz alta enquanto usa a Interface do sistema. Os comentários foram gravadas em vídeos para melhor entender como os usuários interagem com os sistemas.

Técnica 3 (Accessibility Designer) [Takagi 2004]: foi usada com o objetivo de identificar problemas que ocorrem durante o processo de interação de usuários cegos através de simulações feitas com a ferramenta aDesigner. A ferramenta automatizada faz uso de cores para apresentar o tempo estimado para alcançar um conteúdo 
específico, identificando áreas acessíveis e inacessíveis. A escolha dessa técnica se deu pelo fato da técnica possuir uma ferramenta de validação associada que foi usada na fase de testes do presente estudo, e pelo fato da técnica já ter sido experimentalmente validada.

Ferramentas: Para dar apoio à avaliação dos sistemas com usuários cegos foi usado um sistema leitor de tela (Jaws 8.0), sistema navegador Web (Firefox 3.0.4 e Internet Explorer 8) e sistema para gravação de vídeo (Camtasia Studio 6) configurado para capturar as telas durante a interação do usuário, capturando também a voz do participante e do sistema leitor de tela. O sistema operacional do equipamento de teste (laptop) foi o Windows Vista Home Premium. Para validação automática, foi usada a ferramenta aDesigner 2.0.0.

(c) Definição dos sistemas para o estudo: Para delimitar a pesquisa, foram selecionados dois sistemas para serem avaliados, usando dois critérios: popularidade e gratuidade. Foram avaliados dois sistemas síncronos, popularmente conhecidos como salas de bate papo ou chat: sistema de conversação do site da rede SACI e do provedor TERRA.

(d) Avaliação com um simulador automático: Inicialmente foi feita uma avaliação automática de acessibilidade dos sistemas selecionados. Para isso foi usada a ferramenta aDesigner licenciada pela IBM. Tendo como base as tarefas foram definidas quais páginas deveriam ser avaliadas pela ferramenta. Para cada página avaliada pela ferramenta foi seguido o seguinte roteiro: i) carregamento da página com a ferramenta; ii) simulação da página com a opção "cego"; iii) geração de arquivo de erros, função disponível na ferramenta; iv) captura de telas, gerando imagens para serem analisadas posteriormente; v) coleta de dados: total dos erros, pontos a serem verificados por usuários (user check) e informações; vi) tabulação dos dados a partir da lista de erros encontrados: agrupados e quantificados por prioridades; vii) tabulação dos dados a partir da lista de erros gerados: agrupados pelos critérios de navegabilidade, facilidade de uso da aplicação (listenability) e conformidade com as diretrizes; viii) elaboração de gráficos das páginas avaliadas; ix) Análise dos gráficos.

(e) Avaliação com usuários cegos: A definição das tarefas dos usuários foi influenciada pela análise do trabalho apresentado por [Mankoff et al. 2005], onde foi designada uma tarefa para cada site a ser avaliado. As tarefas foram projetadas para simular o uso diário dos sistemas com o objetivo de identificar problemas no decorrer da execução de cada tarefa, sendo entregues aos participantes do teste em arquivo texto, juntamente com uma breve descrição dos objetivos da pesquisa, dos métodos adotados e do software de suporte. Nesse arquivo texto, não foram usadas formatações de parágrafo, fonte ou tabulações que poderiam gerar conteúdo desnecessário para o "leitor de tela" identificar. Essa etapa conteve dois testes: teste preliminar e teste final. O teste preliminar foi aplicado a apenas um usuário e objetivou avaliar o método, ferramentas de apoio e questionário e por fim definir um roteiro de aplicação. $O$ teste final, com os demais usuários, teve como meta identificar problemas que dificultam ou impedem os usuários cegos acessarem sistemas.

(f) Análise dos dados coletados: Nessa etapa foram analisados os resultados obtidos nos dois estudos: na avaliação dos sistemas com os usuários e na avaliação dos sistemas 
com o apoio da ferramenta automática. Os resultados dos questionários, das observações e dos vídeos também foram analisados.

\subsection{Limitações do Método}

A primeira limitação dessa pesquisa foi o fato de ter-se restringido a um único grupo de usuário cegos para testes. Partindo-se da premissa que um sistema Web deve proporcionar respostas a todos os usuários, inclusive aos vários grupos deficiência, optou-se por avaliar a interação apenas com os usuários cegos. A segunda limitação foi definir quais sistemas avaliar. Optou-se por avaliar dois sistemas de comunicação (ou conversação), conhecidos como sistemas de bate-papo.

\section{O Resultado das Análises}

\subsection{Avaliação com Simulador Automático}

Conforme já mencionado, uma pessoa que é cega, ou que possui uma grande deficiência visual, faz uso do leitor de tela que lê em voz alta, o texto disponível nos sites ou em outros sistemas desktop. No entanto, esses programas (leitores de tela) não são muito eficientes com certos tipos de conteúdos, por exemplo, conteúdos gráficos [aDesigner 2008]. Em função disso, para apoiar as análises anteriormente feitas, nessa etapa realizou-se uma avaliação dos dois sistemas selecionados, com o apoio da ferramenta aDesigner, que funciona simulando um usuário com deficiência visual.

Para a avaliação do sistema de conversação da rede SACI foram selecionadas duas páginas do Website. A escolha das páginas se deu com base no objetivo da tarefa, onde o usuário deveria escolher uma sala de conversação (bate papo) e enviar uma mensagem padrão. O objetivo dessa avaliação foi identificar problemas ou possíveis obstáculos que pudessem atrapalhar a conclusão da tarefa.

A avaliação do sistema de conversação do site TERRA envolveu a coleta de dados em páginas do sistema com o apoio da ferramenta aDesigner. O objetivo dessa avaliação foi identificar possíveis problemas que um usuário cego vivencia da página principal do sistema até a página de conversação, onde ocorrem trocas de mensagens.

Esta avaliação possibilitou a identificação de "pontos de verificação", denominação usada nas diretrizes de acessibilidade, que podem representar: problemas reais (error), possíveis problemas que precisam ser verificados com usuários (user check) e informações (info) que visam facilitar o acesso às páginas, bem como favorecer o entendimento do conteúdo disponível. A Tabela 2 ilustra a avaliação global dos sistemas com a ferramenta aDesigner.

Tabela 2. Tarefas Executadas nas Seções de Testes.

\begin{tabular}{l|c|c|c|c}
\hline \multirow{2}{*}{ Sistemas } & \multicolumn{4}{|c}{ Prontos de Verificação } \\
& Error & User Check & Info & Total \\
\hline \hline SACI & 2 & 7 & 71 & 80 \\
TERRA & 160 & 333 & 308 & 801 \\
\hline
\end{tabular}




\subsection{Avaliação com os Usuários Cegos}

A avaliação dos sistemas realizada com os usuários cegos foi divida em dois testes: preliminar e final. O teste preliminar, que foi realizado apenas com um usuário, teve por objetivo verificar o roteiro de testes, a adequação das tarefas e do questionário. Os resultados obtidos serviram para promover melhorias no questionário, que posteriormente foi aplicado aos demais participantes da pesquisa.

\section{1) Resultados do Teste Preliminar}

Com a aplicação desse teste, realizado apenas com um usuário, foi possível verificar e eliminar possíveis problemas que poderiam afetar o resultado final da pesquisa, por exemplo: problemas de incompatibilidade entre os softwares de suporte, a adequação das tarefas, a consistência do questionário, a não limitação do tempo de execução das tarefas. O teste preliminar viabilizou a especificação de um roteiro de teste que foi aplicado aos demais usuários que iriam participar dos testes. A Tabela 3 apresenta o roteiro idealizado nesta etapa.

\section{Tabela 3. Roteiro para a Realização dos Testes.}

\begin{tabular}{|l|}
\hline 1. Verificar a conexão com a Internet; \\
\hline 2. Inicializar o sistema leitor de tela (Jaws); \\
\hline 3. Acessar o arquivo texto das tarefas (tarefas.txt); \\
\hline 4. Inicializar o sistema de navegação Web; \\
\hline 5. Acessar o sistema a ser avaliado; \\
\hline 6. Inicializar o sistema de captura de áudio/vídeo (Camtasia); \\
\hline 7. Informar ao participante o início da sessão; \\
\hline 8. Registrar os comportamentos e comentários do participante; \\
\hline 9. Salvar o arquivo de vídeo em uma pasta destinada ao participante; \\
\hline 10. Se o participante desejar dar continuidade às demais tarefas, acessar o próximo sistema e voltar ao passo 7; \\
\hline 11. Aplicar o questionário. \\
\hline
\end{tabular}

Durante esse teste, o usuário também realizou "reconhecimento do teclado" do laptop que foi usado, e informou que a localização de certas teclas não coincidia com a disposição do teclado do laptop de sua propriedade nem de seu computador. Para fazer o reconhecimento do teclado e das funções do leitor de tela (Jaws) o usuário pressiona uma combinação de teclas (insert +1 ) na janela do sistema leitor. Com esse recurso ativo, ao pressionar as teclas, o usuário consegue receber a informação de qual tecla foi pressionada e a função que executa. Esse procedimento executado no teste preliminar mostrou a necessidade de fazer uso de um teclado padrão para os testes, conectado ao equipamento, objetivando melhor desempenho de todos os demais participantes.

\section{2) Resultados do Teste Final}

É interessante ressaltar que os usuários puderam insistir na execução de cada tarefa, ou seja, não houve limitação de tempo para as suas execuções; a quantidade de sessões foi variável. A seguir estão apresentados os resultados obtidos.

a) Sistemas de Conversação - SACI: A rede SACI é usada para a comunicação e difusão de informações sobre deficiência. Esse sistema disponibiliza link para o sistema de conversação denominado bate-papo SACI onde a principal característica é a acessibilidade. A maioria dos usuários desse sistema são deficientes visuais. Existem três maneiras de usar o sistema de conversação: via navegador, via TelNet ou Papovox (mais indicado para pessoas cegas). Nesse estudo foi usada a opção "via navegador". O Sistema de comunicação SACI possui recursos que não foram evidenciados nos demais sistemas analisados nesse estudo, são eles: 
- Ignorar pessoas indesejáveis, mesmo as que saíram do bate-papo recentemente;

- Conversar com pessoas de outras salas;

- Mudar de sala e de apelido sem sair do bate-papo;

- Criar e administrar salas, bem como registrar salas e apelidos, de modo que só o dono (quem registrou) possa usá-los. Entretanto, salas e apelidos sem uso por 45 dias são descadastrados automaticamente.

Embora esse sistema seja mais direcionado para pessoas cegas, foram constatados problemas de usabilidade no "bate-papo via navegador". Um dos problemas mais recorrente foi: links e botões com descrição inadequada, por exemplo "usr" e "ignorar pvt", que dificultam o entendimento dos participantes novatos.

No entanto, foi possível verificar que a ausência de imagens, flash, propagandas e menus extensos tornaram a interação mais fácil. Dos cinco participantes dos testes, apenas um faz uso constante desse sistema, um não conhecia e três participantes já haviam experimentado mas informaram que o público é muito restrito e portanto não usam.

Embora tenham sido detectados alguns problemas, os cinco participantes conseguiram concluir a tarefa. Apenas um dos usuários não conseguiu enviar a mensagem com a opção "reservadamente". Avaliados os questionários e resultados dos testes, verificou-se que dois fatores favoreceram a conclusão rápida da tarefa.

a. Comandos via teclado: Para facilitar a comunicação dos participantes da sala, o sistema disponibiliza comandos que podem ser executados via teclado, por exemplo: "?quem" (lista os participantes da sala), "?n" (mostra as regras do sistema).

b. Acesso do Usuário: Em oposição ao outro sistema avaliado, o acesso à sala foi muito fácil e rápido. Não há verificação de segurança com imagens, o usuário entra com um apelido, que já pode ter sido cadastrado previamente, e escolhe a sala. Caso ele não selecione uma sala de sua preferência, ele será incluído numa sala pública.

b) Sistemas de Conversação - TERRA: No sistema de conversação TERRA, o objetivo da tarefa foi o envio e leitura de mensagem que dá apoio ao diálogo. Com isso, pretendeu-se identificar e avaliar os problemas presentes na Interface, do sistema em estudo, quando usados por pessoas cegas. Cada participante deveria escolher uma "sala", enviar uma pergunta pré-definida e ler a resposta enviada por outros usuários.

Apenas dois participantes conseguiram enviar a mensagem e só um conseguiu ler a resposta. Três participantes levaram cerca de cinquenta minutos em tentativas de acesso à sala. As principais características das interações são destacadas a seguir:

a. Acesso ao sistema: O sistema TERRA faz uso do CAPTCHA (recurso de imagens) para acesso ao sistema. Porém, três usuários não conseguiram identificar o link que permite acessar o CAPTCHA sonoro e ouvir o conteúdo da imagem. No sistema TERRA esse link foi nomeado como "clique". Um dos participantes que conseguiu ter acesso a sala comentou que o link deveria ser "clique aqui para ouvir conteúdo da imagem". Outro exemplo identificado foi com o uso de uma figura de "porta" para o link que representava a entrada na sala, o leitor de tela leu o nome desse link como "sala 
chat", o ideal seria "entrar na sala". Neste ponto, três participantes comentaram em voz alta que não sabiam como entrar na sala.

b. Menu extenso e redundante: $O$ menu do sistema TERRA, além de possuir muitas opções - aproximadamente trinta e uma opções - é redundante. Alguns links são reapresentados na mesma página, por exemplo, a categoria de sala denominada "cidade", aparece duas vezes na mesma tela. Para uma pessoa que faz uso de leitor de tela fica muito cansativo ouvir repetidas vezes o mesmo link, o que gera confusão para o usuário se localizar na tela e identificar as informações disponíveis.

c. Interação com outros sistemas de suporte: A interação dos usuários desse estudo se deu através do uso do sistema leitor de tela Jaws. Durante a realização dos testes, ocorreram alguns travamentos do sistema leitor de tela, o que em geral é esperado. A análise do questionário revelou que os cinco participantes não haviam experimentado o sistema de conversação TERRA, considerando difícil tanto a navegação do sistema quanto a execução da tarefa. Como o TERRA não faz uso do sistema de conversação do sistema SACI, usada pela maioria de seus usuários cegos, talvez tenha sido esse o motivo das dificuldades encontradas.

\section{Comparação entre as Avaliações}

Esta seção apresenta a comparação dos resultados da validação automática dos sistemas com os resultados da avaliação feita junto aos humanos, gerando contribuições que podem auxiliar os profissionais no desenvolvimento de sistemas mais fáceis e acessíveis aos cegos, além de promover futuras discussões sobre o assunto. A seguir são detalhados os pontos relevantes:

\subsection{O Tempo de Alcance}

É interessante ressaltar que o usuário pôde insistir na execução de cada tarefa. Ou seja, não houve limitação de tempo para as suas execuções. Durante a simulação gerada pela ferramenta aDesigner, para alcançar o "link de discussão" a partir do topo das páginas testadas, o maior tempo gasto foi de setenta e sete segundos, já nos testes com os usuários, esse tempo variou de um a treze minutos.

Embora se tenha identificado alguns fatores que favoreceram a demora para a finalização da tarefa, como a não limitação de tempo e o tipo de navegação usada (com setas ou link-a-link), foi verificado que se o sistema disponibilizasse um "link de salto" para o conteúdo discussão, o tempo seria minimizado.

\subsection{A Navegação não Visual e a Definição dos Links}

As pessoas que enxergam podem usar o movimento dos olhos para rapidamente perceber toda a estrutura de uma página. Já as pessoas que não enxergam usam comandos simples de navegação para "varrer" uma página que foi aberta, percebendo o conteúdo através da audição [Takagi 2004].

Para melhorar o acesso e a navegação de um cego, deve-se disponibilizar informações de orientação para aumentar as suas chances de achar o que procura. Com a análise dos resultados dos estudos com os usuários e com o simulador, foram identificadas relações de dependência entre a definição clara dos links e a orientação do 
usuário durante a navegação não visual e também na obtenção de informações. A seguir apresenta-se alguns pontos observados que exemplificam como a navegação dos usuários cegos depende da definição dos links.

a. Navegação com saltos de links e o link como "ponto de referência": Os resultados dos testes mostraram que a "navegação não visual" foi baseada na leitura de links, onde o usuário "salta de link em link" (com a tecla tab) até localizar o seu objeto de pesquisa. Dois participantes, que nunca haviam experimentado os sistemas iniciaram a navegação com as setas, percorrendo todo o conteúdo para conhecer o ambiente, passando em seguida a navegar com saltos de link a link (com a tecla tab).

Foi também percebido, no estudo com usuários, que os links, além de trazerem um conteúdo específico ao ser selecionado, também servem como "ponto de referência" ou "marcos" numa página (ou tela), o que facilita a localização do conteúdo, ou seja, o objeto de pesquisa (conteúdo) está acima ou abaixo de um determinado link.

Portanto, para facilitar a navegação e também a localização de conteúdos, a recomendação determina que se deve identificar com clareza o destino dos links e o seu significado com um texto que faça sentido ao usuário.

b. Link acessível e os programas interpretáveis: Mesmo que os programas interpretáveis, os applets (programa inseridos em uma página da $\mathrm{Web}$ ) ou outros objetos programados tenham sido desativados ou não sejam suportados, deve-se assegurar que as páginas possam ser usadas. Só em último caso, usa-se uma página alternativa.

$\mathrm{Na}$ avaliação com os usuários esse problema ficou bastante evidente quando os participantes precisaram ouvir os caracteres apresentados numa imagem. Foi disponibilizado link para a reprodução em áudio, no entanto surgiram alguns problemas: abertura de nova janela causou confusão e alguns usuários não sabiam retornar à janela de origem, outros usuários não sabiam como reproduzir o áudio sucessivas vezes até a compreensão total dos caracteres. Foi identificado nos sistemas avaliados que não houve avisos para os usuários que existiriam mudanças da "janela ativa" ou "popups", nova janela que fornece informações diversas, como também propagandas.

Observadas as sessões de testes com os usuários e analisados os questionários, chegou-se a conclusão que a "verificação de segurança" através da digitação dos caracteres, dispostos numa imagem e o surgimento de novas "janelas" foram os problemas vivenciados pelos usuários cegos, mais facilmente detectados em todas as sessões de teste, podendo ser considerados os problemas que mais atrapalharam a execução das tarefas propostas.

c. Usabilidade nos links e uso correto de imagens: Deve-se evitar o uso de textos repetidos (redundância) para diferentes links, assim como textos que não expressem o conteúdo, pois poderão não ser percebidos e conseqüentemente, acessados por pessoas que dependem da leitura textual, por exemplo: "clique aqui, novos links, mais informações, clique" e outros.

No sistema de conversação TERRA, o link que torna possível o usuário ouvir os caracteres para permitir o seu acesso ao ambiente de conversação foi nomeado como "clique", quando deveria ser "clique aqui para ouvir conteúdo da imagem". Isso causou perda de tempo e desgaste para três participantes dos testes. 
O uso de imagens para representar uma informação também deve seguir a mesma regra, dar nomes significativos. Uma figura de uma "porta" em um sistema de conversação, onde é costume usar o termo "entrar e sair da sala", deveria ser lida como "entrar na sala" e não apenas "porta", como usado no sistema de conversação TERRA.

Com os resultados dos testes com os usuários chegou-se a conclusão que embora o avaliador automático possa identificar que os links precisam ser nomeados, o conteúdo significativo dos links só poderá ser percebido e validado pelo usuário.

d. Mapeamento dos links de salto para conteúdo: Os "links de salto para conteúdo" facilitam a navegação do usuário cego, na medida em que ele pode optar por "saltar" diretamente para o objeto da sua pesquisa ou ler toda a tela, o que irá minimizar o tempo de alcance do conteúdo (elemento) desejado.

Foi considerado complexo, durante as sessões de teste com os usuários, o mapeamento dos "links de salto para conteúdo", ou seja, a localização desses links nas páginas dos sistemas avaliados. No entanto, com o suporte de uma ferramenta de avaliação automática, essa verificação foi simplificada, pois o simulador mapeou um dos "links de salto".

Da mesma forma que deve-se disponibilizar os "links de salto" para o usuário cego, também é importante que os desenvolvedores de conteúdo Web possam verificar, durante a validação de um sistema, a presença desses links e principalmente o destino deles, ou seja, se estão direcionando para o lugar certo. Para manter um sistema com fácil acesso essas verificações devem ser feitas constantemente. E esse estudo revelou que essa verificação não é trivial por meio das sessões de testes com usuários.

\subsection{Páginas que Independem de Dispositivos}

A nona recomendação presente nas diretrizes de acessibilidade (WCAG 1.0) instrui sobre projetar páginas de sistema considerando a independência de dispositivos, como: mouse, teclado, voz e outros. Isso significa que a decisão de como acessar e usar o sistema deve partir do usuário, e é claro, o sistema deve estar preparado.

$\mathrm{Na}$ avaliação realizada com os usuários, a interação dos participantes se deu por intermédio do teclado, onde não ficou evidenciada nenhuma função que dependesse do uso de um determinado dispositivo. Porém, na avaliação com o apoio do simulador foi identificado a necessidade de se checar junto ao usuário se há ou não a dependência do uso de mouse para a execução da função relacionada. Por exemplo, no sistema TERRA um ponto foi identificado.

Se confirmados, esses pontos poderão impedir o acesso de pessoas cegas ou de pessoas que acessam o sistema por comando de voz. Portanto, os desenvolvedores de conteúdo Web devem projetar sistemas onde seja possível o uso de grande variedade de dispositivos de entrada de comandos e em seguida realizar validação com ferramenta automática para verificar a acessibilidade.

\subsection{Estrutura da Página e a Influência na Navegação}

Os frames são estruturas que permitem apresentar diferentes documentos em janelas independentes ou sub-janelas. No sistema TERRA, após o reconhecimento de alguns 
frames, na página de conversação, a ferramenta detectou frames sem título, que podem ter sido responsáveis pela complexidade da navegação relatada por alguns participantes.

\section{Considerações Finais}

Para alcançar o objetivo pretendido - avaliar como as pessoas cegas interagem com os sistemas de comunicação $W e b$ - foram selecionados dois sistemas de comunicação Web. Essa seleção baseou-se em temas de estudo que estão sendo discutidos em simpósios sobre fatores humanos e foi motivada pela tendência atual das pessoas se comunicarem. Há também a questão comercial, onde muitas empresas estão fazendo uso desses sistemas para dar suporte ao SAC.

A partir da análise dos resultados foi verificado que para avaliar a acessibilidade e a usabilidade de sistemas computacionais é fundamental fazer uso dos dois métodos de avaliação, testes com ferramenta automatizada e testes com usuários, para gerar o mapeamento dos elementos que efetivamente causam problemas na navegação e para a compreensão do conteúdo.

Os resultados obtidos revelaram que a navegação não visual, realizada por usuários cegos, possui dependência com a definição dos links. Mostrou também, que os links são usados como "pontos de referência" para a localização do usuário na Interface do sistema, onde a contextualização dos links é o "elemento chave" que torna mais fácil o acesso e o entendimento das informações. Por outro lado, agregar cores, imagens e programas interpretáveis aos links poderá gerar a diferença para uma acessibilidade pobre.

A análise dos "pontos de verificação", identificados pela ferramenta automática, indicou que existe também uma relação de dependência entre a estrutura do documento e o ato de navegar em sistemas. Ou seja, a disposição e o contexto de tabelas e frames, usados para organizar as páginas, podem também dificultar a navegabilidade.

Dentre os fatores que influenciaram na avaliação realizada com os usuários, destacaram-se: a definição do sistema leitor de tela e do sistema de navegação $W e b$, a experiência dos participantes com relação ao uso de computadores, principalmente o uso de comandos através da combinação de teclas, uso do ambiente Web e familiaridade com os sistemas avaliados.

$\mathrm{Na}$ avaliação automática, realizada com o apoio do simulador aDesigner, foi identificado "pontos de verificação" que indicam a necessidade de se checar junto ao usuário se existe a dependência do uso de mouse para a execução de funções. É importante enfatizar que o usuário cego navega, pelas páginas (telas) dos sistemas, com o teclado.

A imposição do uso do mouse impede não só o acesso desses usuários, mas também de pessoas que enxergam e que não dispõe do mouse, ou ainda de usuários que preferem executar comandos com a combinação de teclas. O acesso dos usuários, que possuem deficiência ou não, fica comprometido pela imposição do uso de um único dispositivo para a execução de funções.

Os resultados dessa pesquisa podem trazer significativa contribuição para promover a acessibilidade e a usabilidade em sistemas para colaboração, podendo também contribuir para a melhoria dos sistemas de avaliação automática, além de 
beneficiar novas pesquisas, para que em um futuro próximo os sistemas $W e b$ sejam mais facilmente acessados por pessoas cegas.

Entre as principais contribuições dessa pesquisa destacam-se as seguintes:

- A criação de um roteiro para as sessões de testes com usuário cegos;

- Nas avaliações realizadas pela ferramenta os resultados obtidos dependeram de uma nova avaliação com os usuários, já que foram identificados "pontos de verificação" que precisaram ser checados com usuários. Assim, os dois métodos - presencial e automatizado - se complementam e devem ser usados juntos;

- O tempo de alcance de um elemento numa página (figura, texto, link, etc.) é sempre variável e depende normalmente de dois aspectos:

1. o aspecto do usuário, onde deve ser levada em consideração a experiência do usuário com o sistema que está sendo avaliado, o conhecimento do usuário em usar as teclas de atalho e também a experiência com o sistema leitor de tela;

2. a estrutura das páginas, se há presença de frames, tabelas, formulários e links para saltar diretamente para o conteúdo desejado.

- A identificação da dependência da navegação não visual com a definição dos links. Os resultados dos testes mostraram que quando o sistema leitor de tela lê o conteúdo textual de um link, nesse instante, o usuário recebe a informação do que pode ser acessado ou não, conforme a sua decisão (do usuário). Quando um link não possui um texto significativo, o usuário poderá desprezar esse elemento (link) e continuar a sua navegação, em busca do conteúdo pretendido. Foi também verificado que os links funcionam como "pontos de referência" numa página, servindo para o usuário localizar as informações, acima ou abaixo de um determinado link. Assim a navegação não visual, dos usuários cegos, depende de como os links foram definidos;

- A identificação de problemas que afetam a navegação dos usuários cegos, a compreensão do conteúdo e a colaboração. São muitos os elementos que podem gerar problemas na navegação do usuário, como por exemplo: má definição textual dos links, presença de imagens sem conteúdo textual, uso de tabelas sem identificação dos cabeçalhos, frames sem título, uso de cores associado à execução de funções do sistema, ausência de link de salto para conteúdo e de links entre páginas, ausência de mensagens de feedback que informe ao usuário sua localização.

\section{Referências Bibliográficas}

ABNT - Associação Brasileira de Normas Técnicas. (2004). NBR 9050: Acessibilidade de Pessoas Portadoras de Deficiências a Edificações, Espaço, Mobiliário e Equipamentos Urbanos. 
ADesigner. (n.d.). Ferramenta aDesigner. Disponível em: $<$ http://www.alphaworks.ibm.com/tech/adesigner $>$.Acesso: 19/05/2008.

Cybis, W.; Betiol, A. e Faust, R. (2007). Ergonomia e Usabilidade: Conhecimento, Métodos e Aplicações, Novatec.

ENAP - Escola Nacional de Administração Pública. (2007). e-Mag - Modelo de Acessibilidade de Governo Eletrônico. Brasília, Curso a Distância

Freire, A.; Goularte, R. e Fortes, R. (2007). Tecniques for Developing More Accessible Web Applications: a Survey Towards a process Classification. In SIGDOC: Proceedings of International Conference on Design of Communication, pp. 162-169, Texas, EUA.

Harrison, S. M. (2005). Opening the eyes of those who can see to the world of those who can't: a case study. In: Sigcse - Technical Symposium On Computer Science Education, 36, St. Louis. Proceedings. Nova York: ACM, 2004. v. 37. p. 22-26.

Laurel, B. (1990).The Art of Human-Computer Interface Design. Reading, Massachusetts: Addison-Wesley.

Leal Ferreira, Simone Bacellar; Santos, R. e Silveira, D. S. (2007). Panorama da Acessibilidade na Web Brasileira, Anais do EnANPAD, Rio de Janeiro.

Leal Ferreira, Simone Bacellar e Nunes, R. R. (2008). e-Usabilidade, Rio de Janeiro, LTC.

Mankoff, J.; Fait, H. e Tran, T. (2005). Is Your Web Page Accessible? A Comparative Study of Methods of Assessing Web Page Accessibility for the Blind, Proceeding of International Conference on Human Factors in Computing Systems, pp. 41-50, EUA.

Nevile, L. (2005). Adaptability and accessibility: a new framework. In: Conference Of The Computer-Human Interaction Special Interest Group (Chisig) Of Australia On Computer-Human Interaction. ACM International Conference Proceeding Series, Canberra, Austrália, Nova York: ACM v. 122. p. 1-10.

Nicholl, A. R. J. (2001). O ambiente que promove a inclusão: conceitos de acessibilidade e usabilidade. Revista Assentamentos Humanos, Marília, v. 3, n. 2, p. 49-60.

Nielsen, J. (2000). Why You Only Need to Test With 5 Users. Disponível: $<$ http://www.useit.com/alertbox/20000319.html $>$. Acesso: 28/7/2008.

Nielsen, J. e Loranger, H. (2007). Usabilidade na Web, Elsevier, Rio de Janeiro.

Norman, D. A. (1999). The Invisible Computer: Why Good Products Can Fall, the Personal Computer is so Complex, and Information Appliances are the Solution. Massachusetts: MIT Press.

Norman, D. A. e Draper, S. W. (1986). (Orgs.) User Centered Systems Design: New Perspectives on Human-Computer Interaction. Hillsdale: Lawrance Earlbaum Associates.

Pimentel, M. (2006).ComunicaTEC: Tecnologias de Comunicação para Educação e Colaboração, Anais do III Simpósio Brasileiro de Sistemas de Informação, Curitiba. 
Pressman, R. S. (2004). Software Engineering: a Practitioner's Approach, $6^{\mathrm{a}}$ Edition, McGraw-Hill, ISBN: 0071238409.

Queiroz, M. A. (n.d.). Bengala Legal: Cegos, Cegueira, Acessibilidade e Inclusão. Disponível em: $<$ http://www.bengalalegal.com/>. Acesso: 2/04/2010.

Rocha, H. e Baranauskas, M. (2003). Design e Avaliação de Interfaces HumanoCmputador, Nied/Unicamp, Campinas-SP.

Sales, M. B. e Cybis, W. A. (2003). Development of a checklist for the evaluation of the Web accessibility for the aged users In: Latin American Conference On HumanComputer Interaction (ACM International Conference Proceeding Series), Nova York: ACM v. 46. p. 125-33.

Takagi, H. (2004). Analysis of Navigability of Web Application for Improving Blind Usability, ACM Transaction on Computer-Human Interaction, v.14, n. 3.

W3C - Web Accessibility Initiative (WAI) (n.d.). Disponível em: $<$ http://www.w3.org/WAI/>. Acesso: 25/03/2010. 